\title{
Abschied von der Politik und von der $\mathrm{FMH}$
}

\section{Bruno Henggi}

Verantwortlicher Public Affairs FMH

Ständerat Joachim Eder hat sich Anfang letzten Jahres entschieden, bei der Gesamterneuerungswahl der eidgenössischen Räte im Herbst 2019 nicht mehr anzutreten. Im Frühjahr dieses Jahres hat er auch seine Beratertätigkeit für die FMH beendet. Für die FMH war der Zuger FDP-Politiker während zweier Legislaturperioden ein wichtiger Berater und Gesprächspartner. Er war für die Ärzteschaft mit grosser Kompetenz und Integrität tätig.

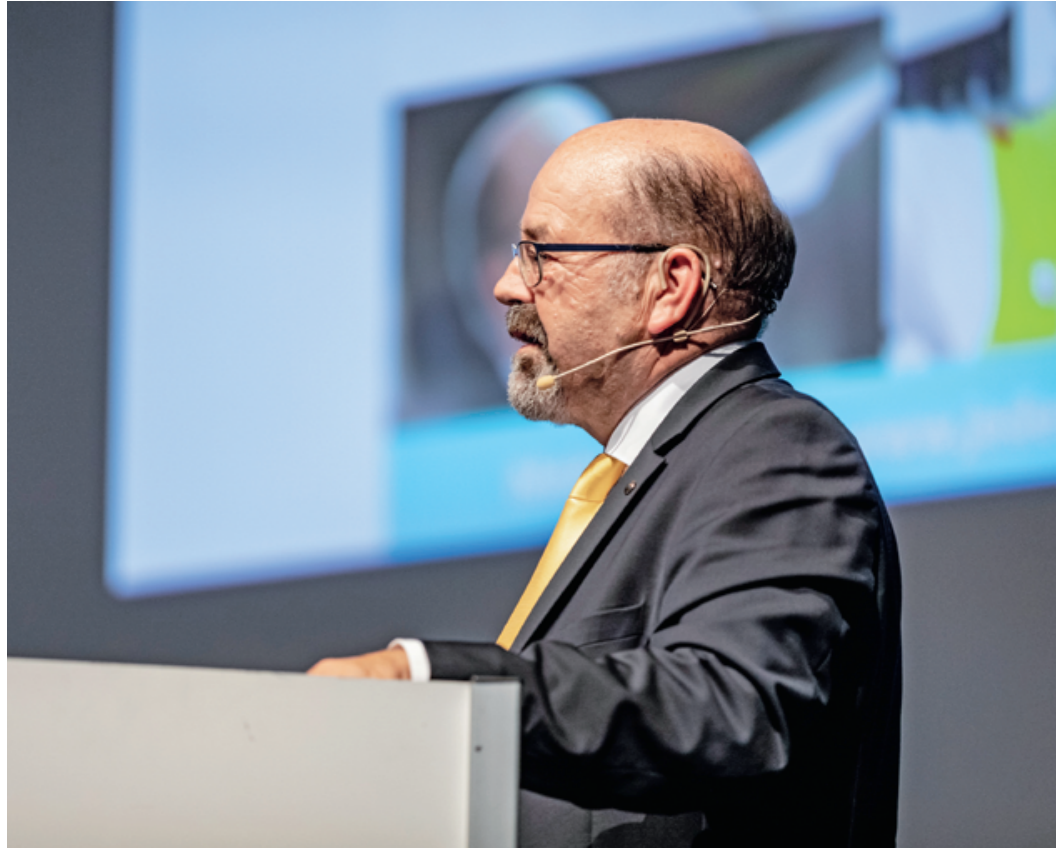

Ständerat Joachim Eder

\section{Berater der FMH}

Für die FMH wurde Joachim Eder mit seinem breiten gesundheitspolitischen Wissen, dem weiten Netzwerk, dem grossen politischen Einfluss und seiner Art, parteiund fraktionsübergreifend Lösungen zu erarbeiten, zu einem wichtigen Gesprächspartner. Die FMH konnte ihn für eine Zusammenarbeit gewinnen, welche zu einem Engagement als Berater im Sounding Board der FMH führte. Dieses dauerte von 2013 bis 2020 - nach seinem Rückzug aus der Politik - an. Diese Zusammenarbeit war noch wertvoller geworden, als Joachim Eder 2015 auch in der Gesundheitskommission Einsitz nahm. Als verantwortungsvoller Milizpolitiker machte sich Joachim Eder mit gesundheitspolitischen Ansichten und Standpunkten von verschiedenster Warte vertraut. So setzte er sich als Präsident des Stiftungsrats 3R für die Forschung nach Alternativen zu Tierversuchen ein - ein Anliegen, das gemeinsam vom Tierschutz und der forschenden pharmazeutischen Industrie getragen wird. Er war Mitglied des Stiftungsrats einer Krankenversicherung, präsidierte auch die Stiftung Gesundheitsförderung Schweiz und engagierte sich als CoPräsident in jenen parlamentarischen Gruppen, die gesundheitspolitische Fragestellungen diskutieren.

Joachim Eder hat einen grossen Teil seiner beruflichen Karriere der öffentlichen Sache gewidmet. Als 32-jähriger Sekundarlehrer wurde er 1983 für die FDP in den Zuger Kantonsrat gewählt. 2001 überlebte er das schreckliche Attentat von Zug und trat in die Zuger Kantonsregierung ein, wo er als Regierungsrat während elf Jahren bis 2012 die Gesundheitsdirektion des Kantons Zug leitete. Und bei der Wahl des eidgenössischen Parlaments 2011 schaffte er auch den Sprung auf die nationale politische Bühne und zog für seinen Kanton in den Ständerat ein.
Er setzte sich für die Forschung nach Alternativen zu Tierversuchen ein.

\section{Aufruf zu souveränem Auftreten}

In seiner mit Leidenschaft vorgetragenen Rede in der Ärztekammer vom Oktober 2019 rüttelte Joachim Eder an einigen Grundpfeilern der Denkweise von Vertre- 
tern des Verbandes der Ärzteschaft. Die FMH dürfe im Gegensatz zum intern immer wieder bemühten Bild der isolierten und ungeliebten Ärzteschaft - ihre politische Interessenvertretung aus einer guten Ausgangslage heraus betreiben. Denn das Image in der Bevölkerung sei gut und die Kompetenz der Ärzteschaft als Gesundheitsakteur anerkannt. Diese komfortable Situation sei zu nutzen, unterstrich der Ständerat. Namentlich sei die starke Position der FMH für den Aufbau und die Pflege dauerhafter Allianzen zu nutzen.

In seiner mit Leidenschaft vorgetragenen Rede rüttelte er an einigen Grundpfeilern der Denkweise von Vertretern des Verbandes der Ärzteschaft.

Das stärke die politische Schlagkraft, sei jedoch auch eine notwendige und gern gesehene Vorleistung für die politische Entscheidfindung im Parlament und werde von Politikerinnen und Politikern sehr geschätzt. Von der FMH erwarte man auch ein offensives Kommunikationsverhalten, positive Botschaften und Stellungnahmen. Es sei der FMH in letzter Zeit zwar gelungen, vom früheren Neinsager-Image wegzukommen. Trotzdem sei in politischen Kreisen immer noch die Einschätzung vorhanden, im Mittelpunkt stünden zu oft der pekuniäre Aspekt der ärztlichen Anliegen und zu wenig die Interessen der Patientinnen und Patienten.

\section{Pflege der Bündnisfähigkeit - konstruktive Politik}

Die Ärztekammer bekam auch Lob zu hören. Ein absolutes Highlight des konstruktiven Dialogs sei das Datum des 12. Juli 2019, als die Tarifpartner FMH und curafutura dem Bundesrat nach über dreieinhalbjähriger Arbeit TARDOC, den neuen ambulanten Tarif für ärztliche Leistungen, zur Genehmigung und zur Inkraftsetzung per 1. Januar 2021 eingereicht hätten. Joachim
Eder sagte, er habe mit Freude von dieser Tatsache Kenntnis genommen. Er gratulierte der Ärzteschaft in aller Form «zu diesem Meilenstein, zu dem viele aus der FMH mit enormer Energie und Leidenschaft beigetragen haben».

\section{Mit einer Stimme sprechen}

Joachim Eder war ein bürgernaher, bürgerlicher, interessierter, integrer und fairer Politiker. Und er war auch Mensch. Auf sympathische Art hat Joachim Eder sein Bedürfnis, als Politiker auch einmal einen Schulterklopfer zu erhalten, zum Ausdruck gebracht. Das Sprechen mit einer Stimme sei im politischen Diskurs sehr wichtig, rief er der Ärztekammer entgegen. Und erinnerte dabei an die Diskussion über das Tabakproduktegesetz in der Gesundheitskommission des Ständerats im August 2019. Aussenminister Ignazio Cassis war gerade in die Kritik geraten, weil am Schweizer Auftritt an der Expo 2020 in Dubai ein Zigarettenhersteller als Sponsor zur Diskussion stand. In der Folge ging ein Ruck durch die Gesundheitskommission des Ständerats, und sie beschloss unter aktiver Führung ihres Präsidenten Joachim Eder, die Voraussetzungen zur Ra-

Auf sympathische Art hat er sein Bedürfnis, als Politiker auch einmal einen Schulterklopfer zu erhalten, zum Ausdruck gebracht.

tifizierung der WHO-Rahmenkonvention zur Eindämmung des Tabakgebrauchs zu schaffen. Was Joachim Eder nicht sagte, indes bekannt war: Er hätte durchaus anerkennende Worte für das klare gesundheitspolitische Signal der ständerätlichen Gesundheitskommission unter seiner Präsidentschaft entgegengenommen. Auch das ist notabene ein Erfolgsfaktor der politischen Interessenvertretung: Ein Lob ist ein wirksames Führungsinstrument. 